\title{
Valores energéticos de diferentes cultivares de milho para aves
}

\section{Energetic values of different corn cultivar for poultry}

\author{
Jeffersson Rafael Henz ${ }^{1 *}$; Ricardo Vianna Nunes²; Paulo Cesar Pozza ${ }^{3}$; \\ Antonio Claudio Furlan ${ }^{3}$; Carina Scherer ${ }^{4}$; Cinthia Eyng ${ }^{5}$; \\ Wagner Thiago Mozzer da Silva ${ }^{1}$
}

\section{Resumo}

Devido ao alto custo que a alimentação representa na produção avícola, torna-se necessário o conhecimento da composição química e energética dos alimentos para formular rações precisas, objetivando melhor desempenho zootécnico e econômico da atividade. Desta forma, o objetivo deste trabalho foi determinar a composição química, os valores energéticos e os coeficientes de metabolizabilidade de diferentes cultivares de milho para aves. Para determinar os valores energéticos foi utilizado o método de coleta total de excretas, com nove cultivares de milho, uma ração referência, tendo quatro repetições e cinco aves por unidade experimental. Os valores de Energia Metabolizável Aparente (EMA) e EMA corrigida para o balanço de nitrogênio $\left(\mathrm{EMA}_{\mathrm{n}}\right)$, variaram de 3113 a $3550 \mathrm{kcal} / \mathrm{kg}$ de matéria natural $(\mathrm{MN})$, e de 3069 a $3473 \mathrm{kcal} / \mathrm{kg}$ de $\mathrm{MN}$, respectivamente. Houve diferença $(\mathrm{P}<0,05)$ entre os coeficientes de metabolizabilidade das amostras de milho, que variaram de 75,80 a $86,65 \%$ para EMA e de 74,75 a $84,96 \%$ para $\mathrm{EMA}_{\mathrm{n}}$, respectivamente.

Palavra-chave: Coeficiente de metabolizabilidade, energia metabolizável, frangos de corte

\begin{abstract}
Due of the high cost that the feeding represents on poultry production, the knowledge about chemical and energy food composition is required to get accurate ration formulas, aiming a better performance and high economy. So, the aim of this work was determine the chemical composition, energetic values and the values of metabolizability coefficients of different corn cultivar for poultries. The total excreta collecting method was used to determine the energetic values, with nine different corn cultivars, one reference ration, four replicates and five birds per experimental unit. The values for apparent metabolizable energy (AME) and AME nitrogen corrected $\left(\mathrm{AME}_{\mathrm{n}}\right.$ ), variety from 3113 to $3550 \mathrm{kcal} / \mathrm{kg}$ $\mathrm{MN}$ and from 3069 to $3473 \mathrm{kcal} / \mathrm{kg} \mathrm{MN}$, respectively. Differences $(\mathrm{P}<0.05)$ were found between the metabolizability coefficients, with variation from 75.80 to $86.65 \%$ for AME and from 74.75 to $84.96 \%$ for $\mathrm{AME}_{\mathrm{n}}$, respectively.
\end{abstract}

Key words: Broiler chicken, metabolizability coefficients, metabolizable energy

\footnotetext{
${ }^{1}$ Discentes de Mestrado no Programa de Pós Graduação Stricto Sensu em Zootecnia da Universidade Estadual do Oeste do Paraná, UNIOESTE, Marechal Cândido Rondon, PR. E-mail: jeffersson_henz@hotmail.com; wtmozer@gmail.com

2 Prof. do Programa de Pós Graduação Stricto Sensu em Zootecnia, UNIOESTE, Marechal Cândido Rondon, PR. E-mail: nunesrv@, hotmail.com

${ }^{3}$ Profs. do Programa de Pós Graduação em Zootecnia, Universidade Estadual de Maringá, UEM, Maringá, PR. E-mail: pcpozza@ yahoo.com.br; acfurlan@uem.br

${ }^{4}$ Bolsista do PNPD no Programa de Pós Graduação Stricto Sensu em Zootecnia, UNIOESTE, Marechal Cândido Rondon, PR. E-mail: carina_scherer@hotmail.com

${ }_{5}^{5}$ Prof ${ }^{a}$. do no Curso de Zootecnia, Universidade Federal da Grande Dourados, UFGD, Mato Grosso do Sul, MS. E-mail: cinthiaeyng@hotmail.com

* Autor para correspondência
} 


\section{Introdução}

A formulação de ração tem como objetivo principal atender as exigências nutricionais dos animais, tornando possível a expressão do ótimo desempenho produtivo. Aliado a isso, existe a preocupação constante dos nutricionistas em produzir rações economicamente viáveis, sendo necessária a constante atualização da composição química e energética dos ingredientes que são utilizados nas fábricas de rações.

A composição das rações para aves se baseia principalmente no milho e farelo de soja, os quais são os principais grãos produzidos no Brasil, e, desta forma, a sua disponibilidade é constante, o que também permite às indústrias a formação de um banco de dados referente à composição nutricional desses grãos. No entanto, fatores como fertilidade do solo, variabilidade genética dos cultivares, condições de plantio, armazenamento e processamento dos grãos, podem alterar o valor nutricional destas matérias primas (NAGATA et al., 2004). Além disso, grãos de má qualidade podem ter a composição química alterada em consequência da redução da biodisponibilidade de nutrientes e, devido à proliferação de fungos, podem causar contaminação por micotoxinas (MAZZUCO et al., 2002).

No Brasil, o sistema orgânico de produção tem crescido durante os últimos anos devido à possibilidade de redução nos custos de produção e pelo preço diferenciado frente ao mercado, pois o termo "orgânico" remete á um produto natural, sem adubos químicos, considerado de maior qualidade. No sistema orgânico são exigidas certas características dos cultivares de milho, tais como, capacidade produtiva, adaptabilidade e rusticidade, devido à necessidade de reduzir a utilização de insumos sintéticos aumentando a necessidade de resgatar e utilizar cultivares menos dependentes de insumos, por serem mais adaptadas às condições locais (SILVA et al., 2007). Deste modo, os grãos produzidos em sistema orgânico tendem a diferenciar em sua composição daqueles produzidos em sistemas convencionais.
Estas variações enfatizam a importância do conhecimento da composição química e do conteúdo energético dos alimentos utilizados para a formulação de rações. A energia influencia diretamente o desempenho das aves, pois é utilizada em processos que envolvem desde a mantença até o máximo potencial produtivo do animal (D’AGOSTINI et al., 2004). Assim, a determinação dos valores de energia metabolizável dos alimentos é fundamental para a formulação de rações para aves e outros animais.

Desta forma, o objetivo deste trabalho foi determinar a composição química, o perfil aminoacídico e os valores de energia metabolizável aparente (EMA) e aparente corrigida para o balanço de nitrogênio $\left(\mathrm{EMA}_{\mathrm{n}}\right)$ de nove diferentes cultivares de milho comerciais, por meio de ensaio de metabolismo com aves em fase de crescimento.

\section{Material e Métodos}

$\mathrm{O}$ ensaio de metabolismo foi conduzido no Núcleo de Estações Experimentais da Universidade Estadual do Oeste do Paraná - UNIOESTE. Foram analisados nove diferentes cultivares de milho, oriundos de propriedades de Marechal Cândido Rondon - PR.

Para determinar a composição química dos diferentes cultivares de milho foram realizadas análises de matéria seca (MS), nitrogênio total $(\mathrm{N})$, extrato etéreo (EE), energia bruta (EB), fibra em detergente neutro (FDN), fibra em detergente ácido (FDA), matéria mineral $(\mathrm{MM})$, cálcio $(\mathrm{Ca})$, fósforo $(\mathrm{P})$, sódio $(\mathrm{Na})$, potássio $(\mathrm{K})$ e magnésio $(\mathrm{Mg})$, de acordo com as metodologias propostas por Silva e Queiroz (2002). O diâmetro geométrico médio (DGM $\mu \mathrm{m}$ ) foi determinado segundo Zanotto e Bellaver (1996). A análise da composição de aminoácidos foi realizada por Espectrofotometria de Refletância de Infravermelho.

Os valores de energia metabolizável aparente (EMA) e aparente corrigida pelo balanço 
de nitrogênio $\left(\mathrm{EMA}_{\mathrm{n}}\right)$ dos alimentos foram determinados utilizando o método de coleta total de excretas com frangos de corte em crescimento, machos, no período de 21 a 31 dias de idade.

De 1 a 21 dias de idade as aves foram criadas em galpão de alvenaria, sobre piso de maravalha, recebendo ração inicial de frangos de corte, à base de milho e farelo de soja e água ad libitum. Aos 21 dias de idade, as aves foram pesadas e transferidas para gaiolas de metabolismo e distribuídas em um delineamento inteiramente casualizado, em nove tratamentos, uma ração referência, quatro repetições e cinco aves por unidade experimental, totalizando 180 aves.

As dietas experimentais foram constituídas de uma ração-referência (RR) a base de milho e farelo de soja (Tabela 1), formuladas para atender as exigências dos animais de 22 a 32 dias de idade, de acordo com as recomendações de Rostagno et al. (2005). As rações experimentais foram compostas de $60 \%$ de RR e $40 \%$ do cultivar de milho a ser avaliado.

Tabela 1. Composição da ração referência (RR), em porcentagem da matéria natural.

\begin{tabular}{|c|c|}
\hline Ingredientes & $(\%)$ \\
\hline Milho & 63,42 \\
\hline Farelo de soja & 31,52 \\
\hline Óleo de soja & 1,51 \\
\hline Calcário & 0,91 \\
\hline Fosfato bicálcico & 1,62 \\
\hline Sal & 0,36 \\
\hline L-lisina HCL (78\%) & 0,11 \\
\hline DL-metionina (99\%) & 0,18 \\
\hline Cloreto de colina $(60 \%)$ & 0,06 \\
\hline Suplemento mineral $^{1}$ & 0,07 \\
\hline Suplemento vitaminico ${ }^{2}$ & 0,12 \\
\hline Anticoccidiano $^{3}$ & 0,05 \\
\hline Promotor de crescimento $^{4}$ & 0,05 \\
\hline Antioxidante $^{5}$ & 0,02 \\
\hline \multicolumn{2}{|l|}{ Composição calculada (\%) } \\
\hline Energia Metabolizável (kcal/kg) & 3.000 \\
\hline Proteína & 19,50 \\
\hline Cálcio & 0,870 \\
\hline Fósforo disponível & 0,41 \\
\hline Lisina disponível & 1,04 \\
\hline Metionina disponível & 0,46 \\
\hline Metionina + cistina disponível & 0,73 \\
\hline Triptofano disponível & 0,22 \\
\hline Treonina disponível & 0,67 \\
\hline Sódio & 0,19 \\
\hline
\end{tabular}

${ }^{1}$ suplemento mineral, conteúdo: $\mathrm{Mg}-16,0 \mathrm{~g} ; \mathrm{Fe}-100,0 \mathrm{~g} ; \mathrm{Zn}-100,0$ g; $\mathrm{Cu}-2,0$ g, $\mathrm{Co}-2,0$ g; I - 2,0 g; e veiculo q. s. p. - 1.000 g. ${ }^{2}$ suplemento vitamínico, conteúdo: Vit. A - 10.000.000 UI; Vit D3 - 2.000.000 UI; Vit E - 30.000 UI; Vit B1 - 2,0 g; Vit B6 - 4,0 g; Ac. Pantotênico - 12,0 g; Biotina - 0,10 g; Vit K3 - 3,0 g; Ac. Fólico - 1,0 g; Ac. Nicotílico - 50,0 g; Vit B12 - 15.000 mcg; Selênio $-0,25$ g; e Veiculo q. s. p. -1.000 g. ${ }^{3}$ Salinomicina $-12 \% ;{ }^{4}$ Avilamicina $-10 \%$; ${ }^{5}$ BHT (hidroxi Butil Tolueno).

Fonte: Elaboração dos autores.

O período experimental teve duração de dez dias, total de excretas, realizada duas vezes ao dia, com sendo cinco dias de adaptação e cinco dias de coleta intervalo de 12 horas, para evitar fermentações. No 
período de coleta, as bandejas foram revestidas com plástico e colocadas sob as gaiolas. Diariamente foi registrada a umidade relativa do ar e a temperatura interna do galpão com termohigrômetro digital.

As excretas foram acondicionadas em sacos plásticos e armazenadas em freezer $\left(-15^{\circ} \mathrm{C}\right)$. Ao término do período experimental, foram determinados o consumo de ração e a quantidade total de excretas produzidas.

Posteriormente as excretas foram descongeladas à temperatura ambiente, homogeneizadas e uma amostra de peso conhecido de cada repetição foi retirada e seca em estufa de ventilação forçada de ar a $55^{\circ} \mathrm{C}$ por 72 horas, para a determinação da amostra seca ao ar (ASA) das excretas. Após a présecagem, as amostras foram moídas e as análises de MS, EB e $\mathrm{N}$ foram realizadas.

Com base nos resultados das análises laboratoriais das amostras de milho, da ração referência e das excretas, foram determinados os valores de energia metabolizável aparente (EMA) e aparente corrigida pelo balanço de nitrogênio $\left(\right.$ EMA $\left._{\mathrm{n}}\right)$, por meio das equações propostas por Matterson et al. (1965). Os coeficientes de metabolizabilidade da energia bruta, em relação aos valores de EMA e EMA, foram calculados segundo Leeson e Summers (2001).

Os valores médios dos coeficientes de metabolizabilidade aparente (CMA) e os coeficientes de metabolizabilidade corrigido pelo balanço de nitrogênio $\left(\mathrm{CMA}_{\mathrm{n}}\right)$ dos diferentes cultivares de milho estudados forma analisados por meio de análise de variância e teste de SNK (StudentNewman-Keuls) ao nível de 5\% de probabilidade utilizando-se o Sistema de Análise Estatística e Genética - SAEG (1999) (verão 8.0).

\section{Resultados e Discussão}

Os cultivares de milho de 1 a 5 avaliados neste estudo são considerados orgânicos e os demais híbridos. A composição bromatológica dos cultivares se encontra na Tabela 2. Fatores como clima (temperatura, umidade do ar e precipitação pluvial), manejo da lavoura pré e pós colheita (semeadura, adubação, colheita e armazenamento) e características genéticas do cultivar podem influenciar na qualidade e na composição química dos grãos produzidos (SANTOS et al., 2005).

Tabela 2. Composição bromatológica e diâmetro geométrico médio (DGM) dos diferentes cultivares de milho, expressos em matéria natural.

\begin{tabular}{lrrrrrrrrr}
\hline \multirow{2}{*}{ Nutrientes (\%) } & \multicolumn{1}{c}{ Cultivares de Milho } \\
\cline { 2 - 10 } & \multicolumn{1}{c}{2} & \multicolumn{1}{c}{3} & \multicolumn{1}{c}{4} & \multicolumn{1}{c}{5} & \multicolumn{1}{c}{7} & \multicolumn{1}{c}{8} & \multicolumn{1}{c}{9} \\
\hline Matéria Seca & 86,02 & 85,64 & 86,46 & 86,20 & 84,37 & 84,98 & 86,03 & 86,30 & 85,99 \\
Proteína Bruta & 10,77 & 8,51 & 10,01 & 10,64 & 9,80 & 10,67 & 8,15 & 7,80 & 8,16 \\
Extrato Etéreo & 5,99 & 5,55 & 4,73 & 4,99 & 4,31 & 4,25 & 4,26 & 4,92 & 4,84 \\
Fibra em Detergente Ácido & 3,12 & 2,50 & 2,52 & 2,92 & 2,93 & 2,45 & 2,72 & 2,35 & 1,96 \\
Fibra em Detergente Neutro & 18,24 & 12,95 & 15,93 & 14,92 & 12,60 & 14,41 & 11,39 & 13,24 & 17,22 \\
Matéria Mineral & 1,50 & 1,50 & 1,22 & 1,32 & 1,49 & 1,64 & 1,15 & 1,35 & 1,16 \\
Sódio & 0,054 & 0,062 & 0,061 & 0,034 & 0,055 & 0,056 & 0,058 & 0,061 & 0,059 \\
Potássio & 0,296 & 0,394 & 0,292 & 0,322 & 0,288 & 0,305 & 0,327 & 0,359 & 0,308 \\
Magnésio & 0,103 & 0,093 & 0,104 & 0,101 & 0,094 & 0,102 & 0,091 & 0,080 & 0,085 \\
Cálcio & 0,021 & 0,010 & 0,011 & 0,006 & 0,007 & 0,009 & 0,009 & 0,013 & 0,012 \\
Fósforo & 0,285 & 0,303 & 0,270 & 0,308 & 0,282 & 0,315 & 0,271 & 0,275 & 0,254 \\
\hline Diâmetro Geométrico Médio $(\mu \mathrm{m})$ & 1138 & 1307 & 1170 & 1186 & 1162 & 1326 & 881 & 756 & 794 \\
\hline
\end{tabular}

Cultivares 1 a $5=$ orgânicos. Cultivares 6 a $9=$ híbridos.

Fonte: Elaboração dos autores. 
As amostras de milho analisadas apresentaram valores de matéria seca entre (84,37 e 86,46\%). Eyng et al. (2009) observaram valores de MS que variaram de 87,83 a $88,81 \%$, enquanto Nagata et al. (2004) verificaram valores de MS entre 86,46 a $87,82 \%$ para diferentes híbridos de milho. O nível de umidade nos grãos de milho é considerado um parâmetro importante, pois no caso de alta umidade e armazenamento por longo prazo em condições de altas temperaturas, pode ocorrer contaminação por fungos, que produzem micotoxinas, causando distúrbios metabólicos nos animais. As diferenças encontradas nos teores de umidade podem estar relacionadas às condições inadequadas de armazenamento dos grãos (D'AGOSTINI et al., 2004).

A proteína bruta, com base na matéria natural, variou de 7,80 a 10,77\%, entre os cultivares de milho avaliados, entretanto, os valores foram semelhantes aos relatados por Freitas et al. (2005a), Santos et al. (2005), Silva et al. (2009) e Piovesan, Oliveira e Araújo (2010), cujos teores de proteína bruta foram 8,$22 ; 8,20 ; 9,77$ e 9,79\%, respectivamente.

De acordo com Vieira et al. (2007) os valores nutricionais podem variar devido à variedade de milho utilizada e no caso da proteína bruta, os valores podem ser influenciados devido a adubação nitrogenada. Para esses autores a proteína bruta é considerada relevante, pois os diferentes cultivares de milho estavam em mesmas condições, porém, com diferentes doses de adubação nitrogenada, podendo influenciar a composição da proteína bruta da dieta. Além disso, no sistema orgânico de produção, estudos têm demonstrado que a adubação orgânica pode aumentar a porcentagem de proteína nos grãos de milho (MATTEUCCI; GUIMARÃES; TIVERON FILHO, 1995). Para Bath et al. (1999) os valores de composição química encontrados em tabelas devem ser utilizados como orientação, e não como informação precisa.

Os valores de extrato etéreo dos cultivares de milho variaram de 4,25 a 5,99\%. Rodrigues et al. (2001) obtiveram resultados inferiores, de 1,88 a 2,46\%. No entanto, Nagata et al. (2004) e Eyng et al. (2009) obtiveram valores semelhantes, que variaram entre 3,78 a $4,77 \%$ e de 3,23 a $4,93 \%$, respectivamente.

Os conteúdos de FDA e FDN observados foram de 1,96 a $3,12 \%$ e 11,39 a $18,24 \%$, respectivamente. Nagata et al. (2004) obtiveram valores superiores para FDA (3,33 a 3,86\%), no entanto, os valores de FDN foram semelhantes (14,13 a 15,90\%).

Altos valores de fibra são correlacionados negativamente com a digestibilidade da matéria seca, extrato etéreo, proteína bruta e da energia do alimento, devido ao aumento da taxa de passagem pelo trato gastrointestinal do animal (MURAMATSU et al., 1991).

Os valores encontrados para matéria mineral variaram de 1,15 a $1,64 \%$ entre os diferentes cultivares de milho, valores superiores aos encontrados por Rodrigues et al. (2001) e Mazzuco et al. (2002), porém semelhantes aos apresentados por Eyng et al. (2009).

A composição dos minerais apresentou variações entre os valores encontrados. Os teores de cálcio variaram de 0,006 a 0,021\%, semelhantes aos encontrados por Nascimento et al. (1998), Carvalho et al. (2004) e Eyng et al. (2009). Entretanto, Rodrigues et al. (2001) obtiveram valores superiores, entre 0,030 e $0,070 \%$. Os teores de fósforo variaram de 0,254 a 0,315\%, ficando entre os valores observados por Eyng et al. (2009). Rodrigues et al. (2001) reportaram valores inferiores aos do presente estudo $(0,190$ e $0,210 \%)$. Quanto aos valores de magnésio, sódio e potássio, variaram de 0,080 a $0,104 \%, 0,034$ a $0,062 \%$ e 0,288 a $0,394 \%$ respectivamente. Nunes et al. (2008) obtiveram valores inferiores para magnésio e potássio, de $0,029 \%$ e $0,134 \%$ respectivamente, entretanto resultados superiores foram encontrados para o sódio $(0,744 \%)$.

$\mathrm{O}$ gérmen de milho contém, aproximadamente, $78 \%$ da constituição mineral do grão, sendo considerada fração rica em minerais, provavelmente 
porque são essenciais ao desenvolvimento da plântula (WATSON; RAMSTED, 1999). De acordo com Pereira et al. (2009), existe um antagonismo entre $\mathrm{Ca}, \mathrm{Mg}$ e $\mathrm{K}$, assim, o aumento na concentração de um destes elementos no meio implica na diminuição da absorção dos outros, o que pode explicar as menores concentrações de $\mathrm{Ca}$ em relação a Mg nos genótipos avaliados pelos autores, e que foi observado no presente trabalho também.

Segundo Eyng et al. (2009), a composição química do milho pode apresentar variações, devido a fatores como potencial genético, nível de adubação utilizado, fertilidade do solo e condições climáticas. No caso das amostras analisadas no presente trabalho, as mesmas eram oriundas de diferentes propriedades rurais, e, desta forma as condições climáticas, de fertilidade e adubação não foram as mesmas para todos as amostras de milho, sendo esperada a variação encontrada na composição bromatológica, o que condiz com a realidade das indústrias de rações, que recebem os grãos de diferentes fornecedores, mostrando assim a importância da atualização constante da matriz nutricional dos alimentos. Além disso, Lima (2000) enfatiza alguns fatores que intervém na qualidade do milho, entre eles se destacam o surgimento de novos cultivares ou novas características e também fatores não genéticos.

Os alimentos podem ser classificados de acordo com o diâmetro geométrico médio das partículas, em grosso (acima de 832,7 mm), médio (valores entre 375,3 a $832,7 \mathrm{~mm}$ ) e fino (valores menores que $375,7 \mathrm{~mm}$ ) (NUNES et al., 2001). Desta forma, considerando a classificação proposta, os cultivares de 1 a 7 podem ser classificados como de granulometria grossa e os cultivares 8 e 9 de granulometria média. Comparando os resultados obtidos com os reportados em literatura podemos observar que existe uma grande variação nos valores comumente encontrados. Rodrigues et al. (2001),
Nunes et al. (2008) e Eyng et al. (2009) encontraram valores de DGM de 874,5 a 904,1 mm, de 569,97 a $598,91 \mathrm{~mm}$ e de 656 a $743 \mathrm{~mm}$, respectivamente, para diferentes cultivares de milho. Vieira et al. (2007) avaliando 45 diferentes híbridos de milho encontraram valores de 366 a $860 \mathrm{~mm}$ para o DGM, e citam que os resultados de diâmetro geométrico médio do milho não são facilmente controlados, pois este depende de suas características físicas e seu fluxo para o moinho, independente do diâmetro da peneira usada.

O tamanho das partículas dos ingredientes é importante quando destinados à fabricação das rações por influenciar na taxa de passagem permitindo a maior ou menor ação enzimática dos sucos digestivos. Já do ponto de vista do consumo alimentar, existe uma preferência das aves por partículas maiores (RIBEIRO; MAGRO; PENZ JUNIOR, 2002). Desta forma, este parâmetro tem importante papel na regulação da ingestão do alimento e da digestibilidade dos nutrientes com consequente efeito no desempenho dos animais. Além disso, o gasto despendido com energia pelos moinhos pode reduzir através da otimização do grau de moagem dos ingredientes (DAHLKE et al., 2001).

Com relação à composição aminoacídica houve variabilidade entre os cultivares de milho (Tabela 3). A composição encontrada no presente estudo se assemelha aos valores reportados por Rostagno et al. (2005) e Gomes et al. (2010). No entanto, Fontes et al. (2007) obtiveram valores inferiores aos encontrados neste trabalho para arginina, isoleucina, metionina, ácido glutâmico, glicina e serina, enquanto que a lisina foi superior, e os demais aminoácidos foram semelhantes. Os cultivares estudados que apresentaram os maiores teores de proteína bruta (1, 3, 4 e 6) foram os responsáveis pelos maiores valores de aminoácidos essenciais (lisina, metionina e treonina). 
Tabela 3. Composição aminoacídica (\%) de nove cultivares de milho na matéria natural.

\begin{tabular}{lccccccccc}
\hline \multirow{2}{*}{ Aminoácidos (\%) } & \multicolumn{7}{c}{ Cultivares de Milho } \\
\cline { 2 - 9 } & 1 & 2 & 3 & 4 & 5 & 6 & 7 & 8 & 9 \\
\hline Metionina & 0,21 & 0,22 & 0,20 & 0,21 & 0,22 & 0,23 & 0,18 & 0,17 & 0,16 \\
Metionina+Cistina & 0,45 & 0,47 & 0,41 & 0,45 & 0,45 & 0,47 & 0,38 & 0,37 & 0,35 \\
Lisina & 0,35 & 0,26 & 0,23 & 0,27 & 0,24 & 0,24 & 0,27 & 0,23 & 0,22 \\
Treonina & 0,38 & 0,39 & 0,30 & 0,37 & 0,36 & 0,41 & 0,30 & 0,32 & 0,27 \\
Arginina & 0,57 & 0,52 & 0,41 & 0,50 & 0,46 & 0,49 & 0,42 & 0,43 & 0,39 \\
Isoleucina & 0,35 & 0,38 & 0,28 & 0,36 & 0,35 & 0,39 & 0,25 & 0,27 & 0,24 \\
Leucina & 1,24 & 1,46 & 1,03 & 1,36 & 1,33 & 1,56 & 0,87 & 0,92 & 0,85 \\
Valina & 0,50 & 0,52 & 0,39 & 0,50 & 0,48 & 0,53 & 0,38 & 0,40 & 0,36 \\
Histidina & 0,33 & 0,33 & 0,26 & 0,32 & 0,30 & 0,33 & 0,25 & 0,25 & 0,24 \\
Fenilalanina & 0,51 & 0,56 & 0,41 & 0,52 & 0,52 & 0,59 & 0,35 & 0,38 & 0,35 \\
Glicina & 0,43 & 0,42 & 0,34 & 0,40 & 0,39 & 0,40 & 0,34 & 0,36 & 0,32 \\
Serina & 0,52 & 0,55 & 0,42 & 0,52 & 0,51 & 0,57 & 0,38 & 0,40 & 0,37 \\
Prolina & 0,91 & 1,03 & 0,80 & 0,99 & 0,95 & 1,06 & 0,75 & 0,75 & 0,71 \\
Alanina & 0,79 & 0,87 & 0,64 & 0,82 & 0,80 & 0,90 & 0,57 & 0,59 & 0,55 \\
Acido Aspártico & 0,70 & 0,70 & 0,53 & 0,67 & 0,65 & 0,71 & 0,54 & 0,54 & 0,50 \\
Acido Glutâmico & 1,91 & 2,17 & 1,56 & 2,03 & 1,95 & 2,26 & 1,39 & 1,46 & 1,34 \\
\hline
\end{tabular}

Cultivares 1 a 5 = orgânicos. Cultivares 6 a $9=$ híbridos.

Fonte: Elaboração dos autores.

O valor nutritivo da proteína está relacionado à proporção de aminoácidos que a compõe. Desta forma, o principal problema nutricional do milho é relacionado ao desequilíbrio de aminoácidos essenciais, como a deficiência de lisina e triptofano e o alto teor de leucina, isoleucina e fenilalanina, sendo a proteína do milho desta forma, considerada como de baixo valor biológico (REGINA; SOLFERINI, 2002). Alguns trabalhos na literatura descrevem que os aminoácidos, como fenilalanina, leucina e isoleucina, em excesso na dieta podem ocasionar redução na absorção de outros aminoácidos como metionina, lisina e triptofano, por competirem pelo mesmo sítio de absorção nas membranas celulares (HENRY et al., 1992; RUTZ, 2002). A determinação do perfil aminoacídico dos ingredientes é um indicador da qualidade protéica dos mesmos, no entanto, é necessário considerar que o aproveitamento biológico dos aminoácidos depende da digestibilidade da proteína.

Os valores de EB (Tabela 4) variaram de 4052 a $4118 \mathrm{kcal} / \mathrm{kg}$ na matéria natural. Os valores mostraram haver diferença quando comparados aos da literatura. Rostagno et al. (2005) e Silva et al. (2005) encontraram valores inferiores, 3925 e 3732 $\mathrm{kcal} / \mathrm{kg}$ na matéria natural, respectivamente.

Neste estudo, os valores de EMA e EMA (Tabela 4) encontrados variaram de 3113 a 3550 e de 3059 a $3473 \mathrm{kcak} / \mathrm{kg}$ na $\mathrm{MN}$, respectivamente. Vários são os fatores relacionados à composição química que podem influenciar nos valores de energia metabolizável, sendo que segundo a literatura o conteúdo de proteína e extrato etéreo e a composição dos ácidos graxos e minerais são os que mais contribuem para essas variações (VIEITES et al., 2000; NUNES et al., 2005). 
Tabela 4. Valores energéticos dos diferentes cultivares de milho e seus respectivos coeficientes de metabolizabilidade, expressos com base na matéria natural.

\begin{tabular}{|c|c|c|c|c|c|c|c|c|c|c|}
\hline \multirow{2}{*}{ Energia (kcal/kg) } & \multicolumn{10}{|c|}{ Cultivares } \\
\hline & 1 & 2 & 3 & 4 & 5 & 6 & 7 & 8 & \multicolumn{2}{|c|}{9} \\
\hline Energia Bruta & 4106 & 4111 & 4023 & 4116 & 4118 & 4095 & 4052 & 4072 & \multicolumn{2}{|c|}{4088} \\
\hline EMA & 3113 & 3139 & 3325 & 3307 & 3318 & 3225 & 3432 & 3280 & \multicolumn{2}{|c|}{3550} \\
\hline $\mathrm{EMA}_{\mathrm{n}}$ & 3059 & 3110 & 3287 & 3245 & 3267 & 3176 & 3366 & 3236 & \multicolumn{2}{|c|}{3473} \\
\hline \multicolumn{11}{|c|}{ Coeficiente de metabolizabilidade (\%) } \\
\hline & 1 & 2 & 3 & 4 & 5 & 6 & 7 & 8 & 9 & $\mathrm{CV}$ \\
\hline CMA & $75,80^{\mathrm{d}}$ & $76,35^{\mathrm{d}}$ & $82,64^{\text {bc }}$ & $80,35^{\text {bcd }}$ & $80,58^{\text {bcd }}$ & $78,75^{\mathrm{cd}}$ & $84,71^{\mathrm{ab}}$ & $80,54^{\mathrm{b}}$ & $86,85^{\mathrm{a}}$ & 2,78 \\
\hline $\mathrm{CMA}_{n}$ & $74,75^{\mathrm{d}}$ & $75,66^{\mathrm{cd}}$ & $81,70^{\mathrm{ab}}$ & $78,85^{\text {bc }}$ & $79,33^{\mathrm{b}}$ & $77,56^{\mathrm{cd}}$ & $83,07^{\mathrm{a}}$ & $79,47^{\mathrm{b}}$ & $84,96^{\mathrm{a}}$ & 2,49 \\
\hline
\end{tabular}

EMA = energia metabolizável aparente; EMAn = EMA corrigida pelo balanço de nitrogênio; CMA = coeficiente da EMA; CMAn $=$ coeficiente da EMAn. Cultivares 1 a 5 = orgânicos. Cultivares 6 a $9=$ híbridos.

Fonte: Elaboração dos autores.

Considerando a composição em nutrientes e os valores energéticos foi observado que a matéria mineral e a fibra bruta afetam negativamente a energia metabolizável do alimento. No caso da matéria mineral, o valor energético do alimento é afetado pela redução da matéria orgânica que é a parte que resulta em produção de energia (NASCIMENTO et al., 2009) e pela possível saponificação das gorduras reduzindo a sua utilização pelas aves (BRUGALLI et al., 1999). Já a fibra da dieta afeta negativamente a energia por aumentar a velocidade de passagem do alimento pelo trato gastrointestinal (SANTOS et al., 2005). Nery et al. (2007) ao avaliarem a energia metabolizável para aves observaram que alimentos com maior teor de PNA's têm os menores valores de energia, confirmando que a fibra pode aumentar a taxa de passagem e reduzir a eficiência das enzimas digestivas. Segundo Freitas et al. (2005b) polissacarídeos não-amiláceos possuem propriedade anti-nutricional pela elevada capacidade de hidratação, aumentando a viscosidade no conteúdo intestinal, diminuindo a acessibilidade às enzimas endógenas e disponibilidade dos nutrientes, reduzindo assim a digestibilidade e absorção de nutrientes.

Os valores de EMA foram, em média, 1,46\% superiores aos valores de EMA ${ }_{n}$. Este fato é normal quando os valores energéticos são determinados com aves em crescimento, devido à retenção positiva de nitrogênio para deposição de tecido protéico, tornando-se mais evidente quando os valores são corrigidos pelo balanço de nitrogênio (NERY et al., 2007).

Os valores obtidos no presente trabalho são semelhantes aos encontrados por Silva et al. (2005) e Nery et al. (2007) que encontraram valores de 3289 e $3275 \mathrm{kcal} / \mathrm{kg}, 3425$ e $3393 \mathrm{kcal} / \mathrm{kg}$, expressos na matéria natural para EMA e EMA, respectivamente. Os valores de $\mathrm{EMA}_{\mathrm{n}}$ apresentados pelos diferentes cultivares de milho mostraram-se inferiores ao citado por Leeson e Summers (1997), que foi de $3749 \mathrm{kcal} /$ $\mathrm{kg}$ na matéria natural.

Os coeficientes de metabolizabilidade relacionam os valores de energia metabolizável com os de energia bruta, sendo que quanto melhor a utilização da energia pelas aves maiores são os coeficientes. Os valores de coeficiente de metabolizabilidade de todos os cultivares de milho foram superiores a $70 \%$, o que demonstra um bom aproveitamento dos nutrientes como energia metabolizável.

Houve diferença significativa $(\mathrm{P}<0,05)$ entre os coeficientes de metabolizabilidade dos diferentes cultivares de milho avaliados, sendo que os valores variaram de 75,80 a 86,85 para CMA e de 74,75 a 84,96 para $\mathrm{CMA}_{\mathrm{n}}$. Resultados semelhantes aos encontrados no presente estudo foram reportados por Nunes et al. (2008), valores estes de $82,77 \%$ para CEMA e de $80,71 \%$ para $\mathrm{CMA}_{\mathrm{n}}$. 


\section{Conclusão}

Os cultivares de milho analisados apresentaram variações na composição bromatológica e aminoacídica, o que pode interferir nos valores energéticos do alimento. A EMA e EMA variaram de 3113 a 3550 e de 3069 a $3473 \mathrm{kcal} /$ $\mathrm{kg}$, respectivamente. O CMA e $\mathrm{CMA}_{\mathrm{n}}$ diferem entre os cultivares de milho, variando de 75,80 a 86,86 e 74,75 a $84,96 \%$, respectivamente.

\section{Referências}

BATH, D.; DUBAR, J.; KING, J.; BERRY, S.; OLBRICH, S. Byproducts and unusual feedstuffs. Feedstuffs, Bloomington, v. 71, n. 31, p. 32-38, 1999.

BRUGALLI, I.; ALBINO, L. F. T.; SILVA, D. J.; GOMES, P. C.; ROSTAGNO, H. S.; SILVA, M. A. Efeito do tamanho de partícula e do nível de substituição nos valores energéticos da farinha de carne e ossos para pintos de corte. Revista Brasileira de Zootecnia, Brasília, v. 28, n. 4, p. 753-757, 1999.

CARVALHO, D. C. O.; ALBINO, L. F. T.; ROSTAGNO, H. S.; OLIVEIRA, J. E.; VARGAS JUNIOR, J. G.; TOLEDO, R. S.; COSTA, C. H. R.; PINHEIRO, S. R. F.; SOUZA, R. M. Composição química e energética de amostras de milho submetidas a diferentes temperaturas de secagem e períodos de armazenamento. Revista Brasileira de Zootecnia, Brasília, v. 33, n. 2, p. 358-364, 2004.

D’AGOSTINI, P.; GOMES, P. C.; ALBINO, L. F. T.; ROSTAGNO, H. S.; SÁ. L. M. Valores de composição química e energética de alguns alimentos para aves. Revista Brasileira de Zootecnia, Brasília, v. 33. n. 1, p. 128-134, 2004.

DAHLKE, F.; RIBEIRO, A. M. L.; KESSLER, A. M.; LIMA, A. R. Tamanho da partícula do milho e forma física da ração e seus efeitos sobre o desempenho e rendimento de carcaça de frangos de corte. Revista Brasileira de Ciência Avícola, Santos, v. 3, n. 3, p. 211217, 2001.

EYNG, C.; NUNES, R. V.; POZZA, P. C.; POZZA, M. S. S.; NUNES. C. G. V.; NAVARINI, F. C.; SILVA, W. T. M.; APPELT, M. D. Composição química e valores energéticos de diferentes cultivares de milho para aves. Revista Brasileira de Saúde e Produção Animal, Salvador, v. 10, n. 1, p. 60-72, 2009.

FONTES, D. O.; DONZELE, J. L.; MASCARENHAS, A. G.; APOLÔNIO, L. R.; SILVA, F. C. O.; FONTES, F.
A. P. V.; CORREA, G. S. S. Composição aminoacídica e digestibilidade ileal de aminoácidos de alimentos energéticos determinados com suínos submetidos à anastomose ileo-retal. Arquivo Brasileiro Medicina Veterinária e Zootecnia, Belo Horizonte, v. 59, n. 1, p. 196-202, 2007.

FREITAS, E. R.; SAKOMURA, N. K.; NEME, R.; BARBOSA, N. A. A. Valores nutricionais do milho termicamente processado, usado na ração pré-inicial para frangos de corte. Arquivo Brasileiro de Medicina Veterinária de Zootecnia, Belo Horizonte, v. 57, n. 4, p. 510-517, 2005a.

FREITAS, F. B.; ZANELLA, I.; CARVALHO, A. D.; RABER, M. R.; BRUM JUNIOR, B. S.; SOUZA, J. F.; FRANCO, S. S.; ROSA, A. P. Avaliação de complexo multienzimático com níveis de trigo para poedeiras na fase de recria. ARS Veterinária, Jaboticabal, v. 21, n. 1, p. 1-6, 2005b.

GOMES, P. C.; GENEROSO, R. A. R.; ROSTAGNO, H. S.; ALBINO, L. F. T.; BRUMANO, G.; MELLO, H. H. C. Valores de aminoácidos digestíveis de alimentos para aves. Revista Brasileira de Zootecnia, Brasília, v. 39, n. 6, p. 1259-1265, 2010.

HENRY, Y.; SEVE, B.; COLLEAUX, Y.; GANIER, P.; SALIGAUT, C.; JEGO, P. Interactive effects of dietary levels of tryptophan and protein on voluntary feed intake and growth performance in pigs, in relation to plasma free amino acids and hypothalamic serotonin. Journal of Animal Science, Champaign, v. 70, n. 6, p. 1873-1887, 1992.

LEESON, S.; SUMMERS, J. D. Commercial poultry nutrition guelph. 2. ed. Ontario, Canada: University Books, 1997. $350 \mathrm{p}$.

Scott's nutrition of the chicken. 4. ed. Ontario, Canadá: University Books, 2001. 591 p.

LIMA, G. J. M. M. Qualidade nutricional do milho: situação atual e perspectivas. In: SIMPÓSIO SOBRE MANEJO E NUTRIÇÃO DE AVES E SUÍNOS, 2000, Campinas. Anais... Campinas: CBNA, 2000. p. 153-174.

MATTERSON, L. D.; POTTER, L. M.; STUTZ, M. W.; SINGSEN, E. P. The metabolizable energy of feed ingredients for chickens. University of Connecticut. Storrs Agricultural Experiment Station, Research Report, v. 7, p. 1-11, 1965.

MATTEUCCI, M. B. A.; GUIMARÃES, N. N. R.; TIVERON FILHO, D. Influência de sucessivos cultivos com adubação orgânica sobre o teor de proteína de uma cultivar de milho (Zea mays L.). Anais da Escola de Agronomia e Veterinária, Goiás, v. 25, n. 2, p. 89-92, 1995. 
MAZZUCO, H.; LORINI, I.; BRUM, P. A. R.; ZANOTTO, D. L.; BARIONI JUNIOR, W.; AVILA, V. S. Composição química e energética do milho com diversos níveis de umidade na colheita e diferentes temperaturas de secagem para frangos de corte. Revista Brasileira de Zootecnia, Brasília, v. 31, n. 6, p. 2216-2220, 2002.

MURAMATSU, T.; KODAMA, H.; MORISHITA, T.; FURUSE, M. Effect of intestinal microflora on digestible energy and fiber digestion in chickens fed a highfiber diet. American Journal of Veterinary Research, Schaumburg, v. 52, n. 7, p. 1178-1181, 1991.

NAGATA, A. K.; RODRIGUES, P. B.; FREITAS, R. T. F. F.; BERTECHINI, A. G.; FIALHO, E. T. Energia metabolizável de alguns alimentos energéticos para frangos de corte, determinada por ensaios metabólicos e por equações de predição. Ciência e Agrotecnologia, Lavras, v. 28, n. 3, p. 668-677, 2004.

NASCIMENTO, A. H.; GOMES, P. C.; ALBINO, L. F. T.; ROSTAGNO, H. S.; RIBEIRO, E. G. Valores de Composição química e energética de alimentos para frangos de corte, determinada por ensaio metabólicos e por equações de predição. Ciência e Agrotecnologia, Lavras, v. 28, n. 3, p. 579-583, 1998.

NASCIMENTO, G. A. J.; RODRIGUES, P. B.; FREITAS, R. T. F.; BERTECHINI, A. G.; LIMA, R. R.; PUCCI, L. E. A. Equações de predição para estimar os valores energéticos de alimentos concentrados de origem vegetal para aves utilizando a metanálise. Revista Brasileira de Zootecnia, Brasília, v. 38, n. 7, p. 1265-1271, 2009.

NERY, L. R.; ALBINO, L. F. T.; ROSTAGNO, H. S.; CAMPOS, A. M. A.; SILVA, C. R. Valores de energia metabolizável de alimentos determinados com frangos de corte. Revista Brasileira de Zootecnia, Brasília, v. 36, n. 5, p. 1354-1358, 2007.

NUNES, R. V.; POZZA, P. C.; NUNES, C. G. V.; CAMPESTRINI, E.; KÜHL，R.; ROCHA， L. D.; COSTA, F. G. P. Valores energéticos de subprodutos de origem animal para aves. Revista Brasileira de Zootecnia, Brasília, v. 34, n. 4, p. 1217-1224, 2005.

NUNES, R. V.; POZZA, P. C.; POTENÇA, A.; NUNIES, C. G. V.; POZZA. M. S. S.; LORENÇON, L.; EYNG, C. NAVARINI, F. C. Composição química e valores energéticos do milho e da silagem de grãos úmidos de milho para aves. Revista Brasileira de Saúde e Produção Animal, Salvador, v. 9, n. 1, p. 82-90, jan./mar. 2008.

NUNES, R. V.; ROSTAGNO, H. S.; ALBINO, L. F. T.; GOMES, P. C.; TOLEDO, R. S. Composição bromatológica, energia metabolizável e equações de predição da energia do grão e de subprodutos do trigo para pintos de corte. Revista Brasileira de Zootecnia, Brasília, v. 30, n. 3, p. 785-793, 2001.
PEREIRA, A. F.; MELO, P. G. S.; PEREIRA, J. M.; ASSUNÇÃO,A.; NASCIMENTO, A. dos R.; XIMENES, P. A. Caracteres agronômicos e nutricionais de genótipos de milho doce. Bioscience Journal, Uberlândia, v. 25, n. 1, p. 104-112, 2009.

PIOVESAN, V.; OLIVEIRA, V.; ARAÚJO, J. S. Predição do conteúdo de aminoácidos essenciais do grão de milho. Ciência e Agrotecnologia, Lavras, v. 34, n. 3, p. 758-764, 2010.

REGINA, R.; SOLFERINI, O. Produção de cultivares de ingredientes de alto valor nutricional: características e benefícios. In: SIMPÓSIO SOBRE INGREDIENTES NA ALIMENTAÇÃO ANIMAL, 2., 2002, Uberlândia. Anais... Campinas: CBNA, 2002. p. 105-116.

RIBEIRO, A. M. L.; MAGRO, N.; PENZ JUNIOR, A. M. Granulometria do milho em rações de crescimento de frangos de corte e seu efeito no desempenho e metabolismo. Revista Brasileira de Ciência Avícola, Santos, v. 4, n.1, p. 1-7, 2002.

RODRIGUES, P. B.; ROSTAGNO, H. S.; ALBINO, L. F. T.; GOMES, P. C.; BARBOZA, W. A. SANTANA, R. $\mathrm{T}$. Valores energeticos o milheto, do milho e subprodutos do milho, determinados com frangos de corte e galos adultos. Revista Brasileira de Zootecnia, Brasília, v. 30, n. 6, p. 1767-1778, 2001.

ROSTAGNO, H. S.; ALBINO, L. F. T.; DONZELE, J. L.; GOMES, P. C.; OLIVEIRA, R. F.; LOPES, D. C.; FERREIRA, A. S.; BARRETO, L. S. T. Tabela brasileira para aves e suínos: composição de alimentos e exigência nutricional. Viçosa: UFV, 2005. 186 p.

RUTZ, F. Proteínas: digestão e absorção. In: MACARI, M.; FURLAN, R. L.; GONZALES, E. Fisiologia aviária aplicada a frangos de corte. 2. ed. Jaboticabal: FUNEP/ UNESP, 2002. p. 135-142.

SANTOS, Z. A. S.; FREITAS, R. T. F.; FIALHO, E. T.; RODRIGUES, P. B.; LIMA, J. A. F.; CARELLO, D. C.; BRANCO, P.A.C.; CANTARELLI, V.S. Valor nutricional de alimentos para suínos determinado na Universidade Federal de Lavras. Ciência e Agrotecnologia, Lavras, v. 29, n. 1, p. 232-237, 2005.

SILVA, C. R.; ALBINO, L. F. T.; ROSTAGNO, H. S.; NERY, L. R.; MESSIAS, R. K. G.; VIANA, M. T. $\mathrm{S}$. Valores energéticos de alguns alimentos usados na alimentação de frangos de corte. In: CONFERÊNCIA DE CIÊNCIA E TECNOLOGIA AVICOLAS, 2005, Santos. Anais... Santos: APINCO, 2005. p. 75.

SILVA, D. J.; QUEIROZ, A. C. Analise de alimentos: métodos químicos e biológicos. Viçosa: UFV, Impresso Universitário, 2002. 235 p. 
SILVA, E. P.; RABELLO, C. B.; LIMA, M. B.; LOUREIRO, R. R.; GUIMARÃES, A. A. S.; DUTRA JUNIOR, W. M. Valores energéticos de ingredientes convencionais para aves de postura comercial. Ciência Animal Brasileira, Goiás, v. 10, n. 1, p. 91-100, 2009.

SILVA, R. G.; GALVÃO, J. C. C.; MIRANDA, G. V.; SILVA, D. G.; ARNHOLD, E. Produtividade de milho em diferentes sistemas produtivos. Revista Verde de Agroecologia e Desenvolvimento Sustentável, Campina Grande, v. 2, n. 2, p. 136-141, 2007.

UNIVERSIDADE FEDERAL DE VIÇOSA - UFV. SAEG. Sistema para análises estatísticas. Versão 8.0. Viçosa, MG: Fundação Arthur Bernardes, UFV, 1999.

VIEIRA, R. O.; RODRIGUES, P. B.; FREITAS, R. T. F.; NASCIMENTO, G. A. H.; SILVA, E. L.; HESPANHOL,
R. Composição química e energia metabolizável de híbridos de milho para frangos de corte. Revista Brasileira de Zootecnia, Brasília, v. 36, n. 4, p. 832-838, 2007.

VIEITES, F. M.; ALBINO, L. F. T.; SOARES, P. R.; ROSTAGNO, H. S.; MOURA, C. O.; TEJEDOR, A. A. Valores de energia metabolizável aparente da farinha de carne e ossos para aves. Revista Brasileira de Zootecnia, Brasília, v. 20, n. 6, p. 2292-2299, 2000.

WATSON, S. A.; RAMSTED, P. E. (Ed.). Corn: chemistry and technology. 4. ed. Saint Paul: American Association of Cereal Chemists, 1999.

ZANOTTO, D. L.; BELLAVER, C. Método de determinação da granulometria de ingredientes para uso em rações de suinos e aves. Concórdia: EMBRAPA Suínos e Aves, 1996. 5 p. (Comunicado técnico, 215). 
